\title{
DEBATT
}

\section{TREATMENT APPROACH PLAYS ROLE IN SOCIAL WORK INTERVENTIONS: A comment to Bergmark and
Lundström}

EDWARD J. MULLEN, JOSEPH SHULUK \& HALUK SOYDAN

In a recent article, Bergmark and Lundström (2011) present a critique of several points we made (Mullen, Shuluk \& Soydan 2011). Bergmark and Lundström make a number of points but most importantly criticize us for denying the importance of the "Dodo Bird" phenomena in explaining social work outcomes. We would like to clarify our position in this regard. In our article, we conclude that there is now a large body of evidence supporting the

Edward J. Mullen, Willma and Albert Musher Professor Emeritus, Columbia University.

Joseph Shuluk, Assistant Research Scientist, New York University.

Haluk Soydan, Professor of Social Work, University of Southern California. effectiveness of a wide range of social work interventions for a wide range of social problems and populations. We further conclude that it is now reasonable to believe that approximately two thirds of clients served by social workers benefit in measurable ways, and that these positive outcomes exist even after controlling for publication and investigator bias, which we acknowledge have been shown to inflate positive outcomes. Because an increasing number of studies have contrasted competing, alternative, credible interventions using some form of comparison group design, we suggest that evidence is beginning to become available about the relative efficacy of alternative interventions 
for specific problems and populations. We conclude that variables common to many social work interventions may explain the generally positive outcomes found in recent reviews of social work outcomes, but that such common factors seem to play a lesser role in social work interventions than in allied psychotherapeutic interventions. We note that William Reid observed the role of common factors, while present in social work intervention evaluations, appears to be diminished by the departure of many social work programs from traditional psychotherapeutic models (Reid, 1997; Reid, Kenaly \& Colvin 2004). Social work differential intervention outcomes have been found when contrasting alternate interventions and specifying a target problem or condition (Reid 1997; Reid et al. 2004) or target system (Gorey, Thyer \& Pawluck 1998). We conclude that there is suggestive evidence supporting differential effectiveness and call for further examina- tion of such effects through comparative effectiveness research.

Looking to the future in our article, we express the hope that comparative effectiveness research in social work, heavily supported by the National Institutes of Health-the principal federal research council in the United States that supports research in social work-produces "more specific knowledge about which interventions, under what conditions, for which problems and for which client groups that have impact and at what cost" (p. 26).

We would like to clarify that while our article was published by Socialstyrelsen, the authors were not paid or commissioned by Socialstyrelsen to pen this article. Rather, as noted in the foreword, our article is an adaptation of a previously published article by Mullen and Shuluk (2011) with expanded attention to role of common factors in explaining outcomes written by Soydan ("Dodo Bird" phenomena).

\section{References}

Bergmark, A., \& Lundström, T. (2011). Socialstyrelsen, dronten och den evidensbaserade praktiken. Socialvetenskaplig tidskrift, 3, 244-251.

Gorey, K. M., Thyer, B. A., \& Pawluck, D. E. (1998). Differential effectiveness of prevalent social work practice models: A meta-analysis. Social Work, 43(3), 269-278. doi:10.1093/sw/43.3.

Mullen, E. J., Shuluk, J. (2011). Outcomes of social work intervention in the context of evidencebased practice. Journal of Social Work. 11(1): 49-63.

Mullen, E. J., Shuluk, J., \& Soydan, H. (2011). Debate on the dodo bird: Does the treatment method play a role in client work. Stockholm,
Sweden: Socialstyrelsen. Retrieved from Socialstyrelsen website: http://www.socialstyrelsen.se/Lists/Artikelkatalog/Attachments/18316/2011-4-15.pdf

Reid, W. J. (1997). Evaluating the dodo's verdict: Do all interventions have equivalent outcomes? Social Work Research, 21(1), 5-16. doi:10.1093/ swr/21.1.5

Reid, W. J., Kenaley, B. D., \& Colvin, J. (2004). Do some interventions work better than others? A review of comparative social work experiments. Social Work Research, 28(2), 71-81. doi:10.1093/swr/28.2.71 